Revista Iberoamericana. Vol. LXIII, Núm. 180, Julio-Setiembre 1997; 503-505

\title{
UN RECUERDO DE DARIO PUCCINI
}

El lugar en que la Universidad de Roma dio su último saludo a Dario Puccini fue el atrio del teatro de la Universidad: un espacio poco formal, y una conmemoración despojada de academicismo (como él habría querido que esta fuera). Las palabras con que lo recordaron su familia, sus colegas y amigos estaban llenas de una conmoción que todos compartimos, pero también hubo algo menos obvio: risas nacidas al evocar una anécdota sobre sus distracciones proverbiales, su conversación en la que una pirueta imprevista del razonamiento hacía tambalear a su interlocutor, sus andanzas de viajero impenitente ... De algún modo, eran un eco de la risa de Darío, irresistiblemente contagiosa, llena de luz. Porque Dario Puccini fue un estudioso erudito, de innumerables lecturas y vastos campos de acción, pero imprimió en su trabajo esa actitud ligera, esa aparente falta de esfuerzo que gobernaba sus gestos.

Un rechazo de la estridencia no le impedía ser definitivo en sus posiciones, cuando lo que estaba en juego era la verdad histórica o los valores civiles. Así su compromiso con América Latina no se expresó sólo en lo literario, sino también en su activa defensa de la democracia contra los totalitarismos y las dictaduras que desgarraron nuestros países. Una actitud que era la prolongación de la participación atenta y crítica que, como intelectual de izquierda, ejerció en la vida política italiana: una elección y un compromiso que mantuvo invariables, desde su militancia juvenil en la Resistencia (y su consiguiente período en la cárcel en el 42) hasta sus últimos días.

Figura compleja de hispanista e hispanoamericanista (y en esto heredero de una tradición familiar ya que su padre, Mario Puccini, novelista y cuentista, fue también traductor, estudioso y trámite de la cultura española e hispanoamericana en Italia), Dario Puccini fue profesor de Literatura Española en la Universidad de Cagliari (Sardegna), y luego de Literatura Hispanoamericana en la Universidad de Roma "La Sapienza". Ya otros han hecho notar cómo su tarea crítica ha conjugado la formación tradicional con la apertura hacia nuevas metodologías, integradas en una amplia visión cultural de raíces históricas, que se completaba además con la investigación en otros campos - sobre todo el del cine.

Memorable en este sentido es su Romancero de la resistencia española (1960, con varias ediciones en italiano, francés y español), así como Miguel Hernández, vita e poesia (edición en italiano 1966, 1970 en español) y La parola poética di Vicente Aleixandre (1976 
italiano, 1979 español). Il segno del presente (1992) recoge distintos trabajos sobre la cultura española: de El Lazarillo de Tormes a Buñuel, en una propuesta interpretativa reveladora de la amplitud de sus intereses y de la agudeza de sus instrumentos de análisis.

En el área hispanoamericana, esclarecedores son los numerosos trabajos que ha dedicado a autores como Borges, García Márquez, Lezama Lima, Neruda, Onetti, Quiroga, Rulfo y es de inminente publicación una obra de vasto alcance que coordinarajunto con Saúl Yurkievich: Storia della civilità letteraria ispanoamericana. Pero creo que su dedicación más apasionada puede percibirse Una mujer en soledad. Sor Juana Inés de la Cruz, una excepción en la cultura y la literatura barroca (1996) en donde retoma un trabajo anterior (Sor Juana Inés de la Cruz. Studio de una personalità del barocco messicano, 1967), rico ya entonces en intuiciones y propuestas inéditas, que aquí se enriquece aún más con un original acercamiento a los aspectos alegóricos, científicos y visuales de la obra de Sor Juana.

Promovió, junto con otros colegas, el Dipartimento di Studi Americani (hoy disuelto, lamentablemente): un enfoque interdisciplinario sobre la totalidad de las Américas. También debemos a Dario Puccini la creación, en 1980, de la revista Letterature d'America, que expresa ese enfoque de conjunto, dedicando tres números monográficos al año a las distintas áreas lingüísticas, y uno, global, a la presencia de temas y problemas comunes en las treas áreas.

Pero hay otro aspecto de Dario Puccini que querría destacar especialmente, desarrollado más allá de los círculos académicos, pero que constituye una continuación natural de su trabajo universitario como hispanoamericanista: su tarea infatigable de traductor, que contribuyó en Italia al conocimiento y la divulgación de la literatura latinoamericana. Suya es la primera traducción en italiano (1955) del Canto general de Pablo Neruda (a quien dedicó su primer trabajo crítico, "Lettura del Canto general", 1950), como también la primera traducción de Jorge Amado (Jubiabá y Os Capitaes da Areia, 1952), y la límpida propuesta en italiano de la obra de Nicolás Guillén, de Gabriel García Márquez, de Juan Carlos Onetti, de Octavio Paz, de Manuel Scorza .... Querría cerrar esta lista, muy incompleta, recordando una empresa de arduo empeño, en la que la experiencia y sutileza de Dario dieron respuesta pareja al desafío: la traducción en verso de La vida es sueño de Calderón de la Barca.

Creo que en el mismo sentido puede leerse su participación como jurado en varios premios literarios, ya que esta actividad fue para Dario una ocasión más para el impulso y la difusión de su amada literatura hispanoamericana en Italia: el premio Mondello (Sicilia), por ejemplo, en el que fueron galardonados, entre otros, Octavio Paz, Juan Carlos Onetti, Juan Gelman.

Su interés por la América viva y palpitante de la actualidad se expresó además en su colaboración en distintos periódos (Messaggero, Paese sera, La Repubblica, l'Unità), a través de reseñas y comentarios. Su presentación en estos medios de la obra de Mempo Giardinelli, Osvaldo Soriano, Vargas Llosa, José Donoso, María Granata, Roa Bastos, Skármeta, Cristina Peri Rossi, Mutis, Saer, Monterroso, Di Benedetto - por citar sólo algunos nombres - contribuyó a crear en el lector común una visión menos esquemática de la literatura hispanoamericana, y al mismo tiempo ofreció al lector especializado una propuesta original y una sugerencia. 
Así Dario Puccini abrió generosamente las puertas de un continente al lector italiano, del mismo modo que generosamente abrió a sus amigos las puertas del refugio que había levantado frente al mar en uno de los paraísos del sur de Italia, Maratea: espacio de su risa, de su escritura, de su conversación y también de un modo de enseñanza.

Rosalba CAmpra 
